Superalloys 2012: 12 $^{\text {th }}$ International Symposium on Superalloys

\title{
A NEW SINGLE CRYSTAL SUPERALLOY FOR POWER GENERATION APPLICATIONS
}

\author{
R.C. Reed $^{1}$, J.J. Moverare ${ }^{2,3}$, A. Sato ${ }^{1}$, F. Karlsson ${ }^{3}$, M. Hasselqvist ${ }^{3}$
}

${ }^{1}$ University of Birmingham, Dept. of Metallurgy and Materials, Edgbaston B15 2TT, UK

2 Linköping University, Dept. of Management and Engineering, SE-58183, Linköping, Sweden

${ }^{3}$ Siemens Industrial Turbomachinery AB Materials Technology, SE-61283 Finspång, Sweden

Keywords: alloy development; single crystal superalloy; oxidation; corrosion; creep deformation, thermomechanical fatigue, Si addition

\begin{abstract}
The properties of a newly developed single crystal superalloy known as STAL-15 - is described which is suitable for use in first stage blades of industrial gas turbines (IGTs). With $15 \mathrm{wt} \% \mathrm{Cr}$ and 4.55 wt.\% $\mathrm{Al}$, the alloy combines good corrosion and oxidation resistance with sufficient creep and fatigue performance. Traditionally, polycrystalline alloys such as IN792 and IN738LC or the single crystal alloy PWA-1483 have been used for this application; unfortunately they display only limited resistance to environmental degradation. The new alloy does not display this weakness and is therefore highly optimised for IGT applications. The new alloy is shown to be an alumina $\left(\mathrm{Al}_{2} \mathrm{O}_{3}\right)$ former; the mechanisms behind the $\mathrm{Al}_{2} \mathrm{O}_{3}$-formation process are studied and the effects arising from changes in the chemical composition have been modelled. In addition, the mechanical properties in terms of creep and fatigue resistance are demonstrated together and the alloy stability evaluated during long term (up to 10,000 hours) exposure. For such applications, the new alloy is superior to existing nickel-based single crystal superalloys designed for aeroengine applications and which are optimised for very high creep resistance. The absence of Re contributes to a lower cost of alloy stock, and enhanced castability.
\end{abstract}

\section{Introduction}

In the industrial gas turbine sector, the requirements for corrosion resistance can vary significantly depending on the fuel used (e.g. natural gas, liquid fuels, biofuels) and the surrounding operating environment (e.g. coastal, desert). Indeed, the demands for fuel flexibility and renewable fuels have increased over the years and corrosion resistance is now in many situations the service-life limiting factor for many components. Furthermore, there has been a drive to increase the efficiency of the engines to reduce costs and to lower $\mathrm{CO}_{2}$ emissions, via more economical fuel consumption. Efficiency enhancement is normally achieved by increasing the firing temperature of the gas turbine which also will lead to increased component temperatures. As a consequence the maximum metal temperature of - for instance a first stage turbine blade in a modern gas turbine - is so high that sufficient oxidation resistance can only be achieved by alloys displaying a continuous $\mathrm{Al}_{2} \mathrm{O}_{3}$ layer. One must also realise that the metal temperature over a turbine blade is not uniform, but varies from approximately $500^{\circ} \mathrm{C}$ at the shank to over $1000^{\circ} \mathrm{C}$ at the hottest region, e.g. at the blade tip. This means that an IGT alloy should ideally display good oxidation and sulphidation resistance in the temperature range $900-1100^{\circ} \mathrm{C}$, and good hot corrosion resistance at $700-850^{\circ} \mathrm{C}$. Finally, high resistance to hydrogen embrittlement at intermediate and ambient temperatures is needed in order to avoid environmental assisted cracking during shut-down periods [1].

Figure 1 illustrates the dilemma faced by the materials engineers and manufacturers working with industrial gas turbines [2].
Candidate alloys for application as turbine blades are given on a graph of their $\mathrm{Al}$ content plotted against their $\mathrm{Cr}$ content, see Figure 1. The resistance to hot corrosion is poor below $12 \mathrm{wt} . \%$ $\mathrm{Cr}$, and the oxidation resistance is deemed to be insufficient for modern high temperature IGTs unless the $\mathrm{Al}$ content is large enough to support the formation of a protective $\mathrm{Al}_{2} \mathrm{O}_{3}$ layer. Standard aeroengine-type alloys in the top left hand corner of Figure 1, such as CMSX-4, Rene N5 and MC2, have a high oxidation resistance but since their $\mathrm{Cr}$ content is below $12 \mathrm{wt} . \%$ their resistance to corrosion is not optimal for IGTs. Similarly, standard IGT alloys such as IN792 and IN738LC have good corrosion resistance on account of their higher $\mathrm{Cr}$ contents, but they do not have the ability to form a protective $\mathrm{Al}_{2} \mathrm{O}_{3}$ layer. While there are a number of old alloys such as U-700 and IN-713LC which do combine at least $12 \mathrm{wt} . \% \mathrm{Cr}$ with an ability to form a protective $\mathrm{Al}_{2} \mathrm{O}_{3}$ layer, their corrosion resistance is not on the level suggested by their $\mathrm{Cr}$ contents due to the detrimental effect of their high Mo content; furthermore they are fairly weak in comparison with modern alloys. Mo was the main strengthening element at the time these alloys were developed, but Mo was partly replaced by W when alloys such as IN738LC were developed in order to improve the hot corrosion resistance.

In this paper, results are presented from a research project which was motivated by the above difficulty. Our intention was to develop a new single crystal superalloy suitable for use in IGT applications, which would reside in the top right hand corner of Figure 1, thus exhibiting a good combination of corrosion and oxidation resistance, and which should be stronger and have a lower Mo content compared to old alloys such as U-700 and IN713LC. Furthermore, on account of its cost and relative scarcity which might possibly lead to supply issues in the future, the use of Re as an alloying element was minimised or hopefully

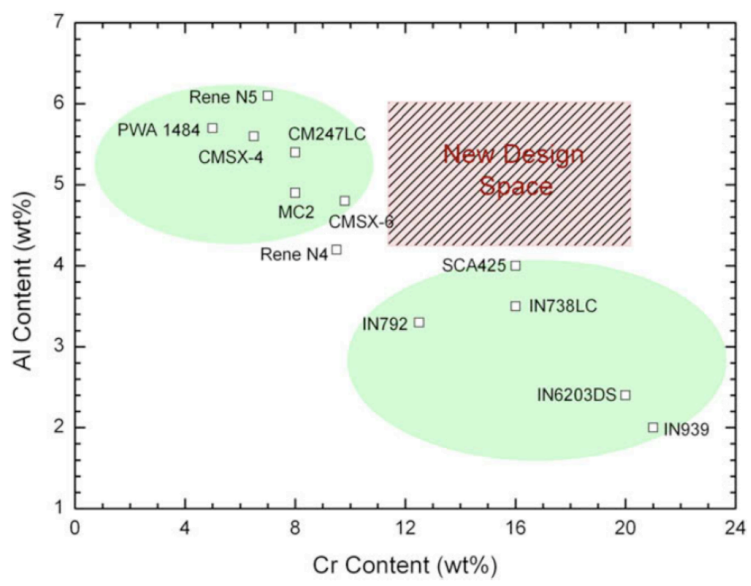

Figure 1. Illustration of the design space identified for the new IGT alloy [2]. 
eliminated. Finally, on account of its intended application, attention was given particularly to the modes of micromechanical damage occurring during both creep and thermo-mechanical fatigue (TMF), and their inter-relationship. Regarding the mechanical properties, it is usually enough to have creep strength comparable to that of the polycrystalline IGT alloy IN792. One can argue that the very high creep strength of alloys such as CMSX-4 is unnecessary when advanced internal cooling systems are utilised in turbine blades for IGTs. However, excellent fatigue resistance is a necessity; this must be manifested by high resistance to fatigue crack initiation in the disc-blade attachment region and high resistance to TMF in the airfoil and platform regions.

\section{Background: Alloy Development History}

Our initial concept in 2006 was to start with the composition of a typical aeroengine alloy, but to reduce the levels of strengthening elements to allow more $\mathrm{Cr}$ whilst not increasing the risk of precipitation of topologically close-packed (TCP) phases. Therefore, a simulation software programmed within the Matlab environment was written for estimation of e.g. $\gamma^{\prime}$ content, $\gamma$ and $\gamma^{\prime}$ compositions and the New PhaComp value. These early calculations followed the methods of Harada et al [3] particularly for the estimation of phase compositions, while the New PhaComp and the lattice spacing formulae were based on Caron [4]. Numerical experiments revealed a potential for corrosion resistant and comparatively strong alloys with an ability to form a protective alumina layer for alloys with $>12 \mathrm{wt} . \% \mathrm{Cr},>4 \mathrm{wt} . \% \mathrm{Al}$, $>7.5$ wt.\% Ta and at most moderate levels of other elements. Later, such calculations were augmented by those made using Thermocalc - particularly for alloys with high Ta levels - as confidence in the accuracy of the thermodynamic databases was gained. This early work led to the composition

\section{Ni-5Co-14Cr-1Mo-2.5W-5.4Al-10Ta-0.4Hf}

[wt.\%] being targetted, and a number of castings were made to get some initial experimental information for this new part of the compositional space. One important result was a measured heat treatment window of at least $70^{\circ} \mathrm{C}$ despite a high $\gamma^{\prime}$ content of about 60 vol. $\%$.

Our work developed further with the patented concept of deriving alloys in this new part of composition space, by replacing Ti and $\mathrm{Nb}$ by (more) $\mathrm{Al}$ and $\mathrm{Ta}$ such that the strength was kept approximately constant. Since Ta has the highest strengthening effect per at.\% as measured by its impact on the lattice spacings, replacement of $\mathrm{Nb}$ and $\mathrm{Ti}$ by Ta enabled a higher $\mathrm{Al}$ content at a similar strength. The comparatively high atomic weight of Ta relative to $\mathrm{Ti}$ and $\mathrm{Nb}$ then automatically led to quite high $\mathrm{Ta}$ levels in wt.\%. Since IN738LC is the most common IGT alloy, it was natural to test this approach on it. Hence the composition

\section{Ni-3Co-16Cr-1.8Mo-2.6W-4.5Al-10Ta-0.4Hf.0.06C-0.05Zr}

[wt.\%] was cast and found to form a protective alumina layer in a cyclic oxidation test at $1100^{\circ} \mathrm{C}$. The levels of $\mathrm{Cr}$, Mo and $\mathrm{W}$ were inherited from IN738LC but the Co level was reduced in order to control and limit the primary creep deformation [5]. The addition of $0.4 \mathrm{wt} . \% \mathrm{Hf}$ was further introduced to improve the compatibility with aluminide coatings.

Once this feasibility study was finished, potential and realistic targets for new alloys within this new part of the composition space were sought. The target properties were set at: (a) IN738LC-level corrosion resistance,

(b) IN792-level creep-rupture resistance, and

(c) oxidation resistance equivalent to CMSX-4 level.

It was realised that this target required single crystal (SX) processing to allow for IN792 level creep-rupture resistance at a $\mathrm{Cr}$ level at about $16 \mathrm{wt} . \%$, as needed for IN738LC level corrosion resistance. Thus, it proved necessary to reduce the level of strengthening elements relative to IN738LC and its derivative somewhat to avoid alloy instability, since some of them are bound in carbides. At this point, it was decided that the SX alloy SCA425 [6, 7], which has a composition in wt.\% of

Ni-5Co-16Cr-1Mo-4W-4Al-2Ti-5Ta

would be a good reference point for the alloy development, as it is an SX alloy and closer to the new part of composition space than IN738LC. When the same alloy design calculations were carried out on SCA425 as had previously been done on IN738LC, the composition

\section{Ni-5Co-16Cr-1Mo-4W-4.6Al-8.5Ta}

was identified. Since the alloy design calculations estimated $1 \mathrm{wt}$. $\%$ Mo and 4 wt. \% W to have a similar strengthening effect as 1.8 wt.\% Mo and 2.6 wt.\% W, and some of the Ta and $\mathrm{Hf}$ in the IN738LC derivative would need to be reduced when going to SX casting, similar alloy compositions were arrived at regardless of where we started. For pedagogical reasons, the alloy development project was then dubbed SCA425+ as it was easier to explain it as 'a moderate change relative to SCA425' rather than as a 'large change relative to IN738LC'. Also, since it was accepted that a leap into a new part of composition space was being made, it was decided to be conservative with respect to TCP precipitation. The result was the prototype SCA425+ with a composition

\section{Ni-5Co-15.5Cr-1Mo-4W-4.55Al-8Ta-0.1Hf-0.03Ce.}

Here we went back to the more standard addition of $0.1 \mathrm{wt} . \% \mathrm{Hf}$, and added a small amount of $\mathrm{Ce}$ to aid clean processing and to neutralise any remaining $S$ which would otherwise reduce the cyclic oxidation resistance. It should be noted that $15.5 \mathrm{wt} . \% \mathrm{Cr}$ in SCA425+ gives the same level of $\mathrm{Cr}$ in at. $\%$ as $16 \% \mathrm{Cr}$ in IN738LC because of the higher density in SCA425+.

The new alloy is now known as Siemens Turbine Alloy STAL-15; it is covered by the patent given in reference [8]. In this paper, the properties of the baseline alloy STAL-15 are presented, and where not explicitly stated otherwise it has a composition equivalent to that of SCA425+ given above. Also considered here are variants containing quantities of $\mathrm{Si}$ and/or Re which are also covered by the patent, and which have proved useful in refining the properties.

\section{Experimental Details}

\section{Mould Preparation and Casting}

An industrial scale investment casting facility at the University of Birmingham was used to prepare single crystal castings in the form of $15 \mathrm{~mm}$ diameter rods of length $150 \mathrm{~mm}$, see Figure 2 . Typically, three rods were cast in each run with a withdrawal speed of $\sim 200 \mathrm{~mm}$ per hour. Ceramic moulds were prepared from alumina, silica and zircon in the usual way; the final mould thickness was $\sim 6 \mathrm{~mm}$. These were de-waxed in a steam furnace for 5 mins and then sintered at $1000^{\circ} \mathrm{C}$ for an hour in air, prior to casting. The casting stock was melted by Ross \& Catherall in Sheffield, UK to industry-leading standards. Chemical analysis indicated less than $7.2 \mathrm{ppmw}$ of sulphur in the stock, so that - 

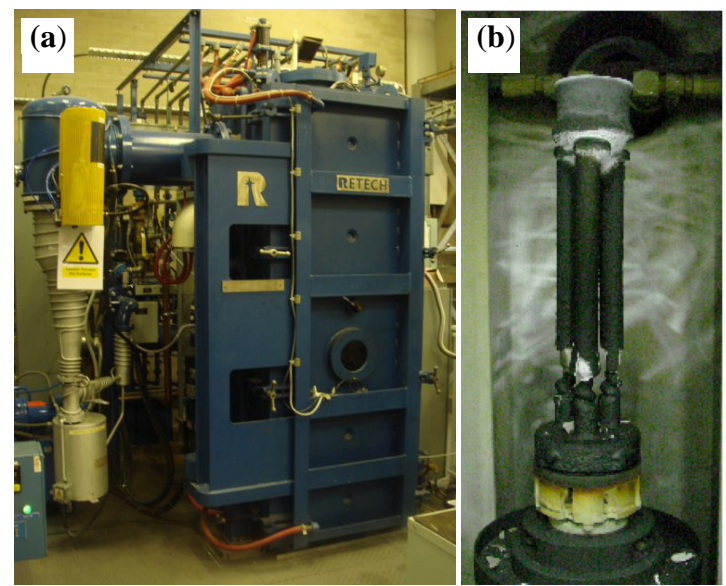

Figure 2. (a) Bridgman casting furnace in the University of Birmingham and (b) typical mould used for single crystal bars in this study.

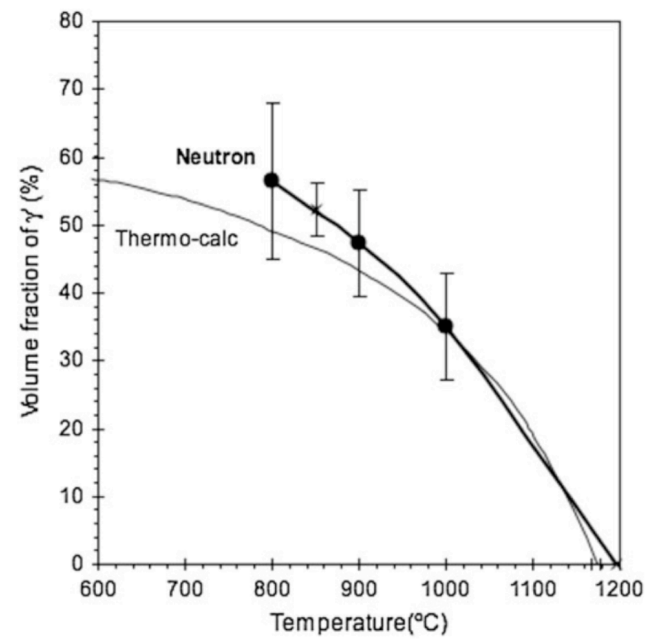

Figure 3. Volume fraction of $\gamma^{\prime}$ as a function of temperature for STAL-15, measured by neutron diffraction plus DSC and predicted by ThermoCalc software using the Ni database ver.6.

since the oxidation temperatures used here are $1000^{\circ} \mathrm{C}$ or lower and the tests carried out isothermally - any influence of this element on oxidation performance will be negligible [9-11]. Casting was carried out under the vacuum of better than $10^{-4} \mathrm{~Pa}$. The single crystal bars were carefully removed from the mould, and then sand blasted. In order to confirm whether the cast bar contained surface defects, the bars were macro etched using $\mathrm{HCl}$ $+5 \sim 10$ vol. $\% \mathrm{H}_{2} \mathrm{O}_{2}$ solution. No freckles were observed.

\section{Heat Treatment}

Differential scanning calorimetry (DSC) of a fully heat-treated specimen of STAL-15 indicated a $\gamma^{\prime}$ solvus temperature of $1196^{\circ} \mathrm{C}$ and a solidus temperature of $1318^{\circ} \mathrm{C}$ [12]. These experimental observations were compared with thermodynamic calculations using Thermocalc [13] and a very good agreement was found, see Fig.3. Solutioning of STAL- 15 was performed at $1300^{\circ} \mathrm{C}$ without any evidence of incipient melting, see Fig.4. The effect of temperature and time on the $\gamma^{\prime}$ microstructure developed during
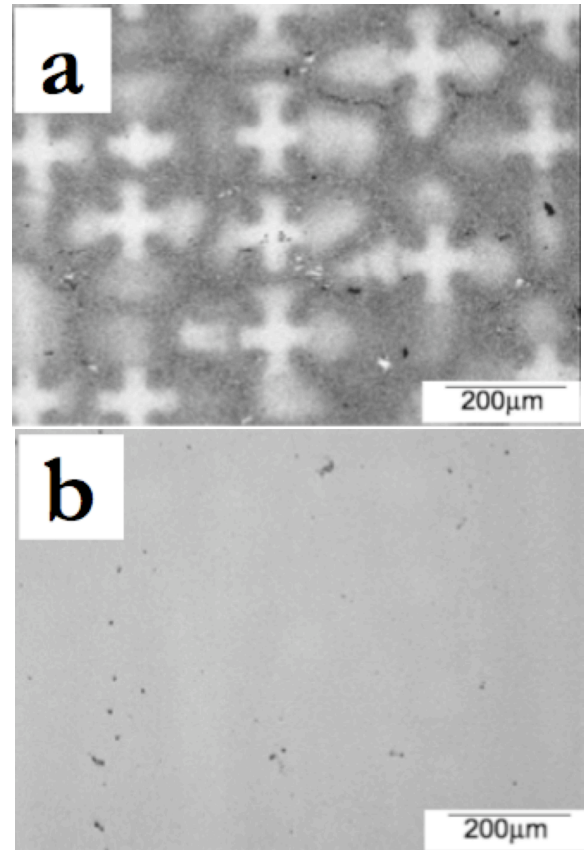

Figure 4. Optical micrographs of STAL-15 (a) as-cast (b) after $1300^{\circ} \mathrm{C} 2$ hours.

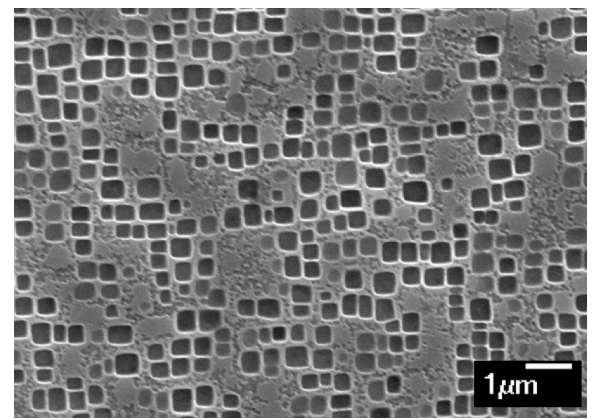

Figure 5. SEM micrograph of STAL-15 after $1300^{\circ} \mathrm{C}$ for 5 hours solutioning followed by ageing at $1100^{\circ} \mathrm{C}$ for 6 hours followed by 20 hours at $850^{\circ} \mathrm{C}$.

primary ageing has been studied, since these need to be chosen carefully for optimised mechanical properties. The mechanical properties of several different microstructures have been verified by creep and fatigue testing $[12,14]$. Based on these observations the following heat treatment conditions are proposed for STAL-15:

- Solutioning $1280^{\circ} \mathrm{C}$ for $1 \mathrm{~h} \rightarrow 1300^{\circ} \mathrm{C}$ for $5 \mathrm{hrs}$, air cooling

- Primary age $1100^{\circ} \mathrm{C}$ for $6 \mathrm{hrs}$, air cooling

- Secondary age $850^{\circ} \mathrm{C}$ for $20 \mathrm{hrs}$, air cooling

This thermal cycle also fits most of the standard coating cycles. The total volume fraction of $\gamma^{\prime}$ phase is calculated to be $48 \%$ at the secondary ageing temperature. This is between IN738LC and IN792. The majority of the $\gamma^{\prime}$ phase precipitation is present as more or less cubic particles with a size of approximately $0.4 \mu \mathrm{m}$. Small amount of finer $\gamma^{\prime}$ phase precipitates in the $\gamma$ channels between the larger precipitates. The resulting microstructure is illustrated in Figure 5. 

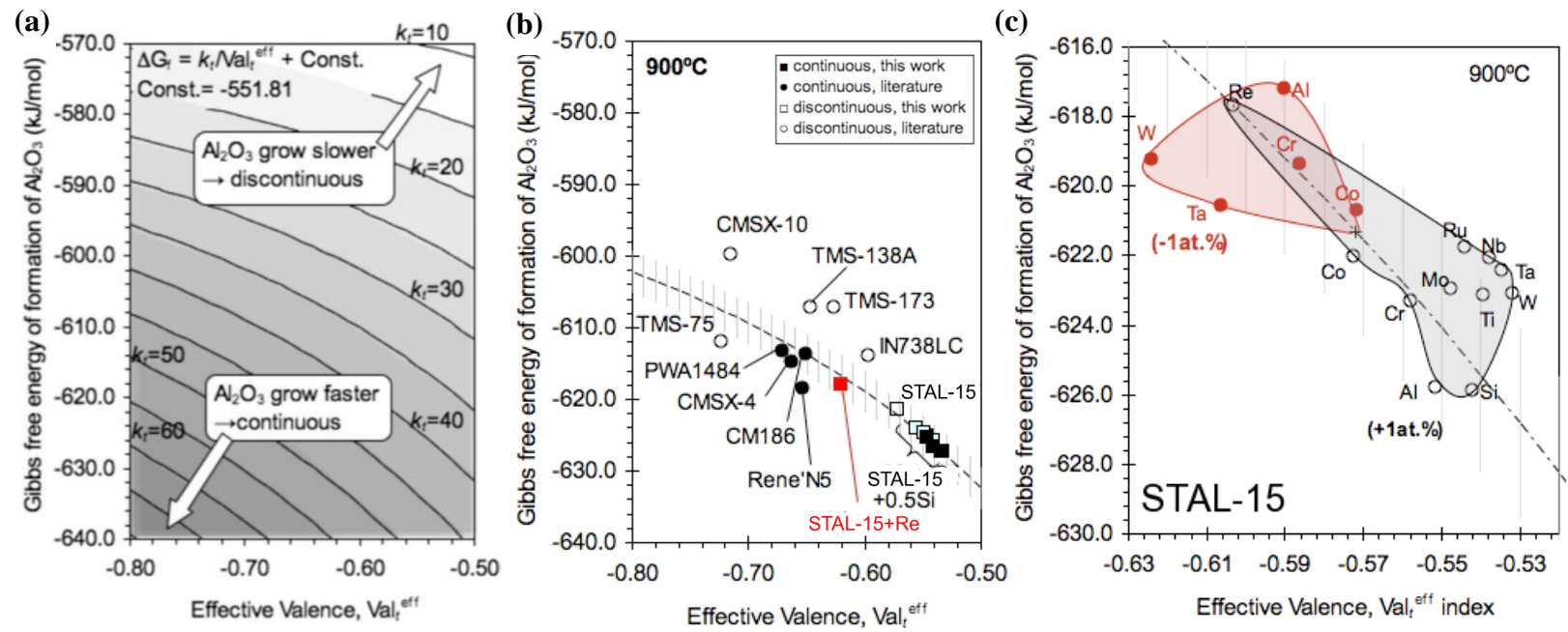

Figure 6 (a) Illustration of the oxidation diagram concept. (b) Oxidation diagram showing the proposed threshold of $\mathrm{Al}_{2} \mathrm{O}_{3}$ layer formation at $900^{\circ} \mathrm{C}$ and (c) the effect of alloying element on the oxidation diagram of STAL- 15 at $900^{\circ} \mathrm{C}$. Reproduced from [15].

\section{Oxidation Behaviour}

\section{Oxidation Diagram of Nickel-Based Superalloys}

The design of accurate models to allow the oxidation resistance of nickel-based single-crystal superalloys to be estimated as a function of their chemical composition is a significant challenge. A complicating factor is the chemical complexity of these alloys; with ten or more elements present many different oxide products are possible including $\mathrm{Cr}_{2} \mathrm{O}_{3}, \mathrm{Al}_{2} \mathrm{O}_{3}, \mathrm{TiO}_{2}, \mathrm{Ta}_{2} \mathrm{O}_{5}$, and $\mathrm{WO}_{3}$ as well as a range of different spinel phases. In practice, alloys which form an alumina scale $\left(\mathrm{Al}_{2} \mathrm{O}_{3}\right)$ exhibit the greatest resistance to oxidation and have therefore gained the highest attention. However, some compositions oxidise more readily than others, despite their being alumina formers, and models which account for these effects would be tremendously useful. As part of the development project, Sato et.al. [15] developed a model capable of predicting whether any given alloy composition will form a continuous alumina scale or not. Broadly speaking, an effective valence index denoted Val $t^{\text {eff }}$ has been proposed, which depends upon the impurities inherited from the substrate during alumina formation. Furthermore, it was found that the composition of the $\gamma$ phase in these materials - and thus the elemental partitioning occurring - appears to play a crucial role in the formation of alumina. When estimates are made for Val $t^{\mathrm{eff}}$ and the thermodynamic driving force for the formation of alumina, the concept of an oxidation diagram can be used to predict whether any given alloy is likely to be an alumina former. This is illustrated for a range of different superalloys in Figure 6. Note in Fig.6b that continuous alumina forming alloys (solid symbol) lie towards the bottom left of the diagram and are distinct from those in which alumina formation is discontinuous.

\section{Oxidation Diagram for Alloy Design}

Fig.6c shows the effect of alloying element on the oxidation diagram. Here, the addition of 1 at. $\%$ of $\mathrm{Al}, \mathrm{Cr}$ and $\mathrm{Si}$ are considered to be beneficial for the alumina formation. Interestingly, the calculation suggested that the removing 1at.\% $\mathrm{W}$ can be significantly beneficial. Considering the mechanical properties (see later part), other suggestions arising from these quantitative calculations include (i) replacement of $\mathrm{W}$ and/or Mo with Re; and (ii) substitution of Ni by Co. Note however that Co additions are reported to deteriorate $\mathrm{Al}_{2} \mathrm{O}_{3} /$ metal bonding toughness [16]; thus this was not recommended. In order to test the hypothesis (i), not only STAL-15 but also a new prototype single crystal superalloys were prepared. STAL-15 alloy was used as the base alloy. STAL-15 contain $4 \mathrm{wt}$. $\%$ of $\mathrm{W}$ to aid creep strengthening, but $2 \mathrm{wt} . \%$ of $\mathrm{W}$ has been substituted by the equivalent quantity of $\mathrm{Re}$ - the new alloy being denoted STAL-15+Re, with its composition

\section{Ni-5Co-15.5Cr-1Mo-2W-4.55Al-8Ta-0.1Hf-0.03Ce-2Re.}

It can be seen from Fig.6b that the $\mathrm{W}->$ Re substitution (taking STAL-15 to STAL-15+Re) pushes its position on the diagram towards alloys such as Rene N5 and CMSX-4 which are known to exhibit excellent oxidation resistance due to their being good alumina formers, but this should be confirmed accordingly.

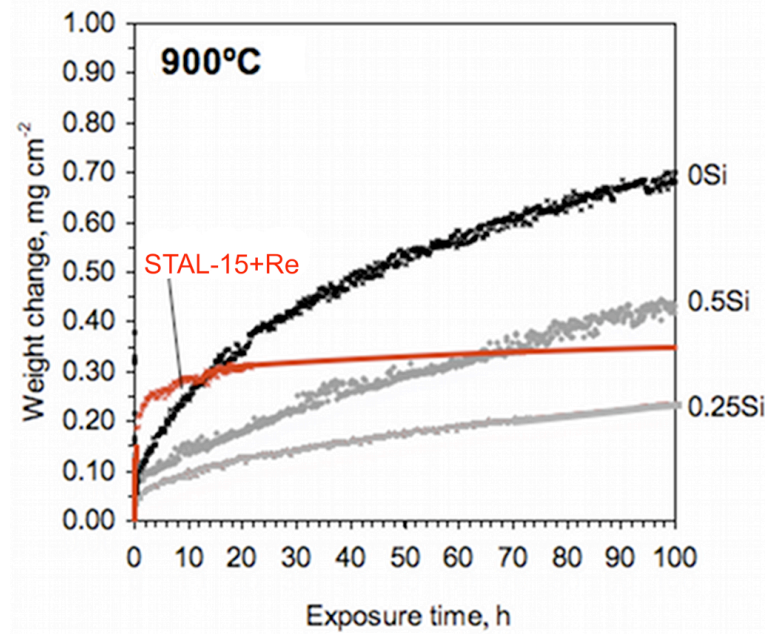

Figure 7. Weight changes observed in STAL-15 with and without $\mathrm{Si}$, and STAL-15+Re during static exposure at temperatures of $900^{\circ} \mathrm{C}$. 


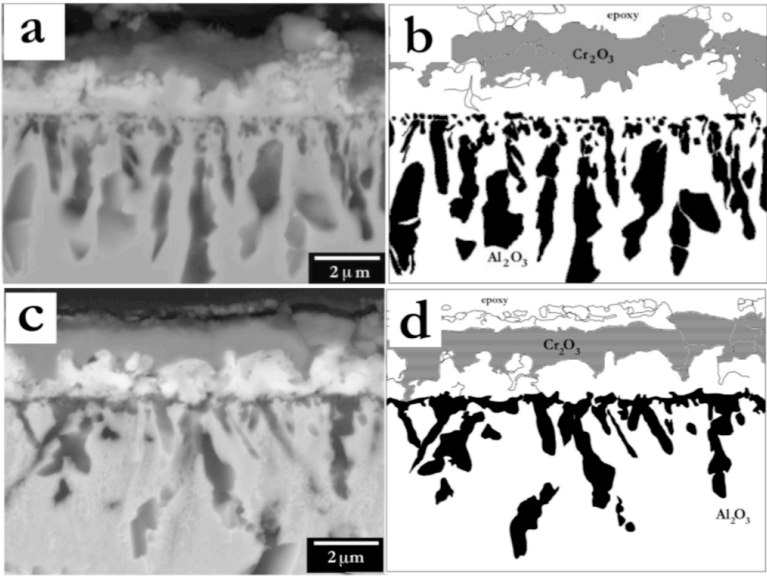

Figure 8. FEG-SEM micrographs of (a) STAL-15 and (c) STAL-15+Re exposed at $900^{\circ} \mathrm{C}$ for 100 hours, at dendrite core region. Note that (b)\&(d) are the sketches of (a)\&(c), respectively.
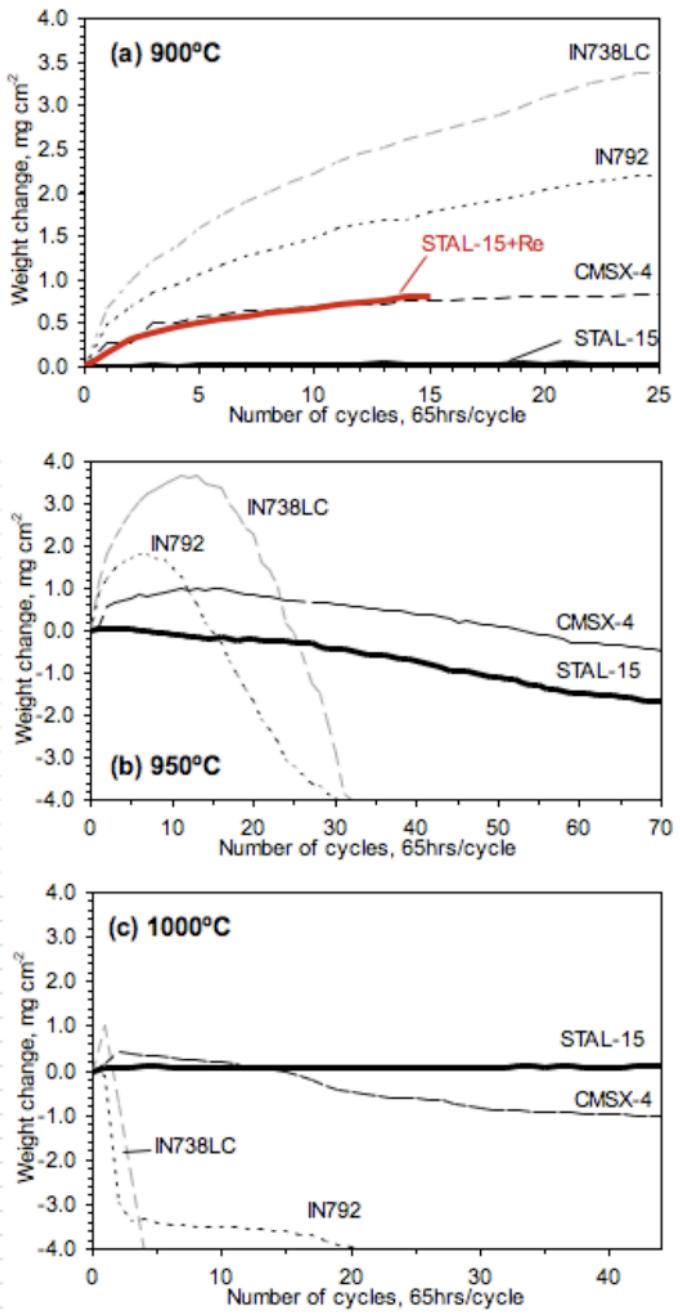

Figure 9. Cyclic oxidation behaviour ( 65 hour cycle) for selected alloys at (a) $900^{\circ} \mathrm{C}$, (b) $950^{\circ} \mathrm{C}$ and (c) $1000^{\circ} \mathrm{C}$.

\section{Isothermal Oxidation}

The weight changes measured during isothermal oxidation testing at $900^{\circ} \mathrm{C}$ are given in Fig.7. A first notable point is that the weight gain accumulated by STAL- 15 is significantly altered by the substitution of W by Re. Fig.8 illustrates the cross-sections of (a) STAL-15 and (c) STAL-15+Re after exposure at $900^{\circ} \mathrm{C}$ for 100 hours, respectively. Backscatter electron images in the SEM indicate the presence of three different oxide species; these are identified as $\mathrm{Cr}_{2} \mathrm{O}_{3}, \mathrm{Ta}_{2} \mathrm{O}_{5}$ (or perhaps $\mathrm{NiTa}_{2} \mathrm{O}_{6}$ ) and $\mathrm{Al}_{2} \mathrm{O}_{3}$. Internal oxidation is prevalent in both STAL-15 and STAL-15+Re, see Fig.8. Moreover, higher resolution observations confirm the formation of the sub-scale alumina on STAL-15 (Fig.8a and 8b); for STAL-15+Re, there is prevalent alumina internal oxidation but this phase forms a thin layer which is virtually continuous, beneath the external scale, see Fig.8c and $8 \mathrm{~d}$, so that it is on the verge of being protective. This observation is at odds with the common belief that Re-alloying is detrimental to oxidation; it is however consistent with the oxidation diagram concept (Fig.6b).

\section{Cyclic Oxidation}

The resistance against cyclic oxidation has been evaluated using a 65 hours cycle at three different temperatures, see Figure 9 At $900^{\circ} \mathrm{C}$, all alloys show a positive mass gain while at higher temperatures the traditional IGT alloys such as IN738LC and IN792 suffer from spallation of the oxide scale. However, STAL-15 shows a very good resistance against cyclic oxidation and it appears that the alloy forms an adherent protective alumina scale up to at least $1050^{\circ} \mathrm{C}$ under the test conditions applied. This is comparable to the oxidation behaviour of CMSX-4 and thus one of the main targets for the new alloy has been fulfilled.

A second interesting observation from these experiments is that the oxidation behaviour is worse at $950^{\circ} \mathrm{C}$ compared to $1000^{\circ} \mathrm{C}$, which highlights the importance to bridge the gap between protective chromia formation at low and intermediate temperatures and protective alumina formation at high temperatures.

Third, STAL-15+Re and CMSX-4 [17] are both found to be a continuous alumina former at $900^{\circ} \mathrm{C}$; therefore, the similar oxidation kinetics found between STAL-15+Re and CMSX-4 may be driven by the thickening of an alumina. On the other hand, STAL-15 is a sub-scale alumina former at $900^{\circ} \mathrm{C}$, and its oxidation is controlled by that of chromia. Since STAL-15 perform better than STAL-15+Re or CMSX-4, it is found that the chromia ratecontrolling alloys can perform better than the alumina ratecontrolling alloy at $900^{\circ} \mathrm{C}$.

Finally, the W->Re substitution (from STAL-15 to STAL-15+Re) accelerated the weight gain during the cyclic exposure at $900^{\circ} \mathrm{C}$ (Fig.9a), and the reason is considered as follows. Since it is confirmed that the substitution of W->Re accelerate the formation of a continuous alumina layer, this substitution decreases the dissociation pressure, or make the alloy oxidisable under the low partial pressure of oxygen. Owing to the fact that the cyclic exposure causes the formation of oxide crack (where the partial pressure of oxygen is low), it is likely that STAL-15+Re oxidise more than that in STAL-15. In other words, it seems that STAL-15+Re was modified too much in terms of cyclic oxidation. For alloy design prospective, it can be concluded that candidate alloys may not necessarily to be a continuous alumina former at 


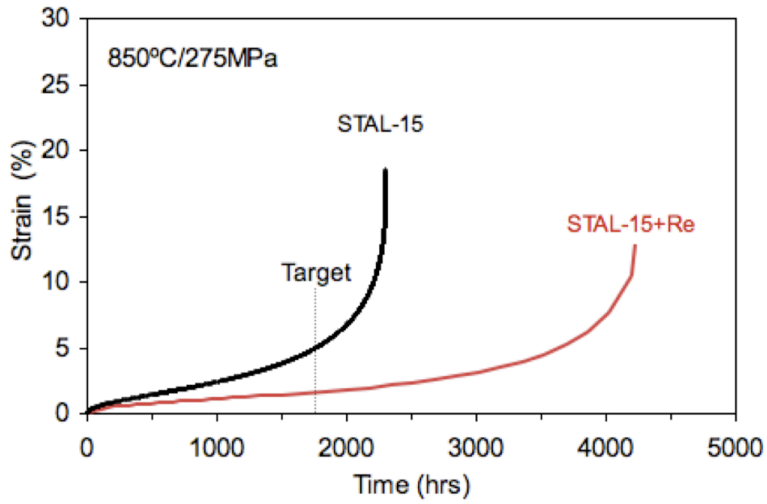

Figure 10. Creep strain vs. time curves for STAL-15 and STAL- $15+\operatorname{Re}$ at $850^{\circ} \mathrm{C} / 275 \mathrm{MPa}$.

$900^{\circ} \mathrm{C}$, as long as the alloys can form a continuous chromia layer to prevent alloys from oxidising.

\section{Mechanical Properties}

\section{Creep}

Creep testing have been performed at $750^{\circ} \mathrm{C}$ and $850^{\circ} \mathrm{C}$ and at two different stress levels for each temperature. Figure 10 shows the creep strain vs. time curves for STAL-15 under the creep condition of $850^{\circ} \mathrm{C} / 275 \mathrm{MPa}$. STAL-15 shows longer creep rupture lives than that of the traditional IGT alloy IN792 in this creep condition. Interestingly, microstructural observation indicated that dislocation activity was limited within matrix, see Fig.11; implying that the creep lives of candidate alloys for IGT should further be improved by controlling dislocation climb activity. Here, likewise to the previous section, this hypothesis should also be confirmed experimentally. Again, STAL-15 and STAL-15+Re were used for this.

Figure 10 also shows the creep strain vs. time curve for STAL- $15+$ Re under creep conditions of $850^{\circ} \mathrm{C} / 275 \mathrm{MPa}$. Creep deformation was significantly improved by the substitution of $\mathrm{W}$ by $\mathrm{Re}$, which is in good agreement with the creep merit index theory developed in [2]. The 1 pct creep properties have been benchmarked against other alloys such as CMSX-4, IN792 and IN738 using the Larson-Miller parameter, see Fig.12. The 1 pct creep properties of STAL-15 and STAL-15+Re are comparable to that of the traditional IGT alloy IN792 but are far from the behaviour displayed by second generation single crystal alloys such as CMSX-4. However, the results are in line with the targets for this new alloy.

\section{Fatigue}

The fatigue resistance of STAL-15 has been evaluated under two different conditions. The first test condition is isothermal low cycle fatigue (LCF) testing of a notched specimen at $500^{\circ} \mathrm{C}$. This type of testing is representative of the loading conditions in the root section where the blades are attached to the discs via a fir-tree coupling. Here the stresses arise mainly from the centrifugal forces acting on the blades; anisothermal effects are normally neglected due to the moderate temperature. The second test condition is out-of-phase thermomechanical fatigue (TMF) where the temperature is cycled between $100^{\circ} \mathrm{C}$ and $950^{\circ} \mathrm{C}$. This type of

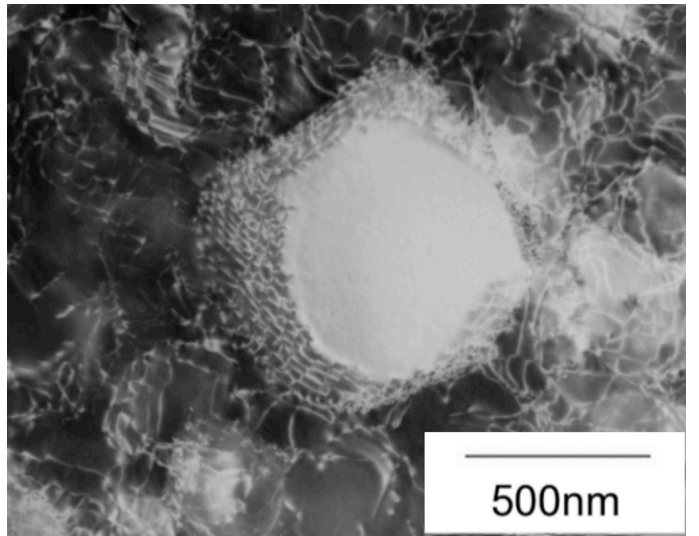

Figure 11. TEM micrographs of STAL-15 after creep rupture testing at $850^{\circ} \mathrm{C} / 275 \mathrm{MPa}$ [12]. Note that first ageing condition for this specimen was $1120^{\circ} \mathrm{C}$ for $24 \mathrm{hrs}$, followed by air cooling.

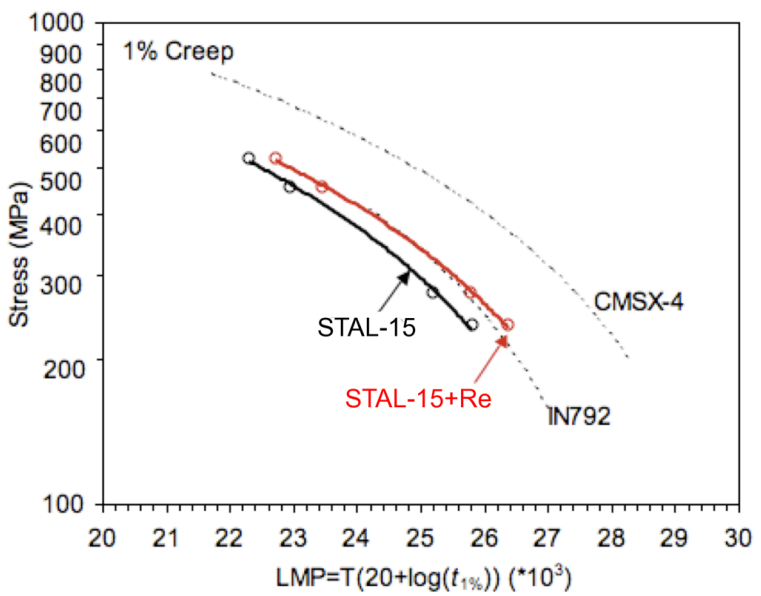

Figure 12. 1pct creep stress versus the Larson-Miller parameter for selected alloys.

testing represents the loading conditions in so called "hot-spots" which typically can be found on the airfoil and on the platform region of the blade. All fatigue tests have so far been done on specimens oriented along the [001] direction. In Figure 13(a), the LCF resistance of notched specimens at $500^{\circ} \mathrm{C}$ is compared. One can see that the LCF life of STAL-15 at typical blade root temperatures is significantly higher compared to both CMSX-4 and PWA-1483. However, STAL-15 does not match up with the exceptionally good behaviour seen in SCA425Hf

In Figure 13(b), the OP TMF $100-950^{\circ} \mathrm{C}$ resistance is compared for different alloys. It can be seen that STAL-15 is better than SCA425Hf but not as good as CMSX-4. One can also see that due to the lower elastic modulus in the $\langle 001\rangle$ direction all single crystal alloys are significantly better than the conventional cast alloy IN792. A significant difference between CMSX-4 and the high Cr-alloys in terms of deformation behaviour during OP TMF testing has been noticed during the testing. Both alloys develop very localised deformation bands which extend across the entire cross-section of the specimen; moreover the fracture surface is normally purely crystallographic and occurs along one of the 

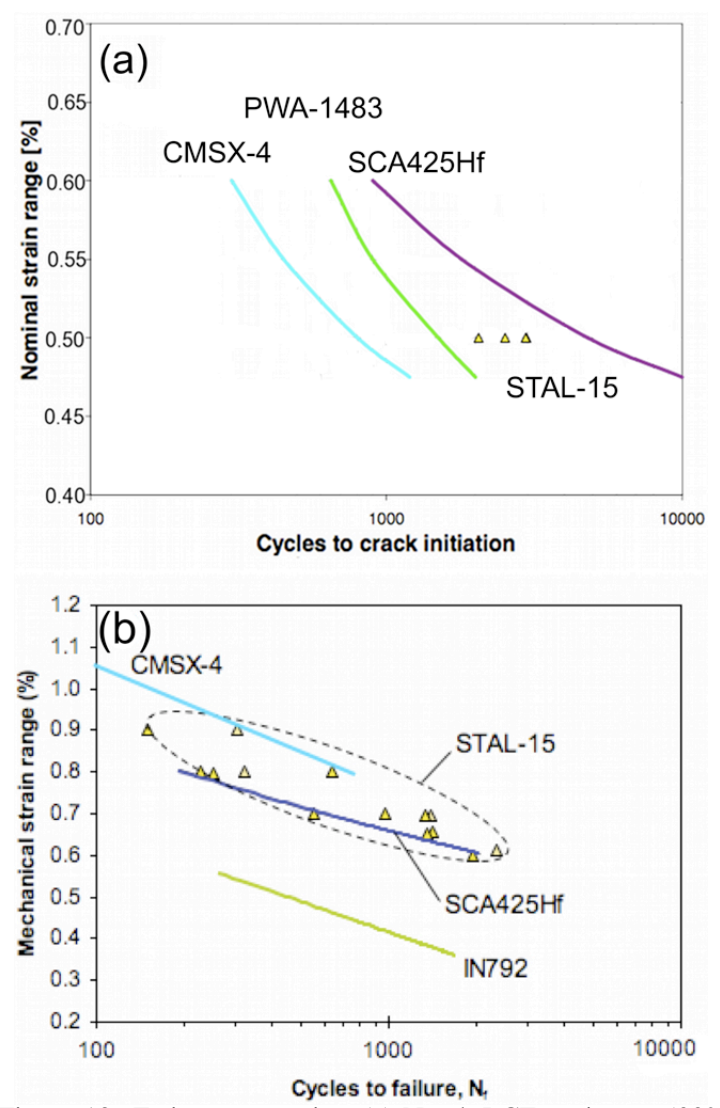

Figure 13 Fatigue properties: (a) Notch LCF testing at $500^{\circ} \mathrm{C}$, (b) Out-of-phase TMF testing $100-950^{\circ} \mathrm{C}$.

$\{111\}$ planes. The main difference is that while twinning is the main deformation mechanism in CMSX-4 during OP-TMF cycling [18], twinning is only rarely observed in SCA425Hf under similar loading conditions. Instead, shearing seems to be the main deformation mechanism in later material. Furthermore, the highly localised deformation in CMSX-4 has been found to promote the precipitation of $\mu$, a topologically close packed phase (TCP). This behaviour is rarely observed in STAL-15. The difference in deformation mode (twinning versus shearing) is probably best attributed to a difference in stacking fault energy (SFE) between the two materials, indicating that SFE is an important parameter for the TMF behaviour in single crystal Ni-base superalloys. The TMF data - and in particular the influence of microstructure and minor element composition - will be discussed in another paper in this volume [19].

\section{Role of Si Addition to STAL-15}

\section{Effect of Si on the Oxidation Resistance}

Figure 7 also shows the weight changes recorded during the TGA analysis for alloys with and without $\mathrm{Si}$ at $900^{\circ} \mathrm{C}$. No significant spallation of oxide was observed. When Si doping is introduced, a beneficial effect is found at lower temperatures. Figure 7 reveals that $0.25 \mathrm{wt} \% \mathrm{Si}$ addition is the most beneficial for oxidation. This piece of information is important since $\mathrm{Si}$ additions will increase the risk for precipitation of detrimental TCP phases, see the following section.
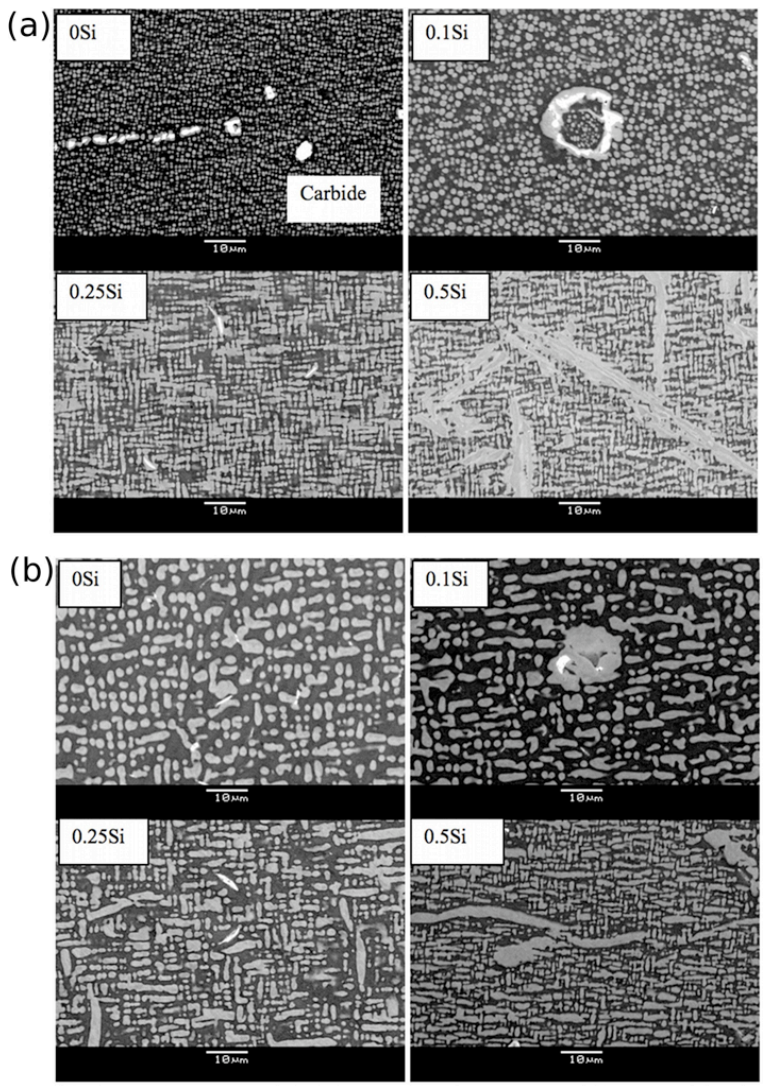

Figure 14 Microstructure of STAL-15 with different Si additions after 10,000 hour exposure at (a) $900^{\circ} \mathrm{C}$ and (b) $1000{ }^{\circ} \mathrm{C}$.

\section{Alloy Stability}

The addition of Si will increase the risk of detrimental TCP phases during service at elevated temperature. So far, exposures of STAL-15 with different $\mathrm{Si}$ additions have been made at two different temperatures $\left(900^{\circ} \mathrm{C}\right.$ and $\left.1000^{\circ} \mathrm{C}\right)$ up to 10,000 hours. The corresponding microstructures can be seen in Figure 14. No TCP phases were found in STAL-15 up to 10,000 hours exposure; indicating the very high phase stability. The conclusion from these experiments is that it is feasible to add $0.25 \% \mathrm{Si}$. Higher $\mathrm{Si}$ content $(0.5 \mathrm{wt} . \%)$ promotes the formation of a $\mathrm{Cr}$-rich needle-like phase at $900^{\circ} \mathrm{C}$, but not at $1000^{\circ} \mathrm{C}$. The addition of $0.5 \% \mathrm{Si}$ is therefore not recommended. For 0.25 wt.\% Si, Hf-Si particles were present at both $900^{\circ} \mathrm{C}$ and $1000^{\circ} \mathrm{C}$; yet the volume fraction of this phase is very small. The addition of $0.25 \% \mathrm{Si}$ is therefore considered to be an acceptable level. In addition, we have nevertheless adjusted the $\mathrm{Cr}$ and $\mathrm{W}$ levels down relative to baseline STAL-15 in order to keep a good margin with respect to TCP precipitation. A suitable Si-containing composition then becomes

Ni-5Co-15Cr-1Mo-3.7W-4.55Al-8Ta-0.1Hf-0.03Ce-0.25Si.

The addition of $\mathrm{Si}$ makes the difference between solvus and solidus smaller, but a significant heat treatment window is retained. The mechanical properties of STAL-15 - including the Si-containing variant - will be discussed further in this volume [19], with particular emphasis on thermal mechanical fatigue. 


\section{Summary and Conclusions}

The following conclusions can be drawn from this work:

1. A new single crystal superalloy STAL-15 has been developed specifically for use in industrial gas turbine applications. A good balance of environmental and mechanical properties are displayed.

2. In laboratory-based casting trials, single crystal superalloys have been produced reliably and consistently, with no evidence of casting defects such as freckles. The solutioning window for heat treatment is wide, and optimised primary ageing treatments have been identified.

3. The isothermal and cyclic oxidation resistance is superior to most other superalloys, specifically on account of its high $\mathrm{Cr}$ content, reasonable Al content and absence of Ti. The evidence indicates that it is an alumina former, particularly at temperatures of $1000^{\circ} \mathrm{C}$ or beyond. The alumina scale formation capability can be enhanced by doping with small quantities of $\mathrm{Si}$.

4. The creep performance is comparable to that of the alloy IN792, which it is intended to replace. The TMF performance is superior to it and is indeed comparable to CMSX-4, despite the absence of Re. This seems to be in part due to creep relaxation processes in compression which occur during out-of-phase thermal cycling.

5. Computer modelling methods contributed strongly to the isolation of the composition of STAL-15, and the relatively small number of make/test iterations required in the laboratory to optimise its composition.

\section{Acknowledgements}

The authors would like to thank Siemens Industrial Turbomachinery AB in Finspång Sweden for financing this work. The advice of Prof. John Knott, Prof. Nick Green, Prof. Hugh Evans and Dr. Mary Taylor at the University of Birmingham is acknowledged with gratitude.

\section{References}

1. M. Nazmy, J. Denk, R. Baumann, A. Kunzler, Environmental Effects on Tensile and Low Cycle Fatigue Behavior of Single Crystal Nickel Base Superalloys, Scr. Mater., 48 (2003) pp. 519-524.

2. R.C. Reed, T. Tao, N. Warnken, Alloys-by-Design: Application to Nickel-Based Single Crystal Superalloys, Acta Mater., 57 (2009) pp.5898-5913.

3. H. Harada, T. Yokokawa, K. Ohno, T. Yamagata, M. Yamazaki, Calculation of Gamma-Prime GammaEquilibrium in Multicomponent Nickel-Base Superalloys, in: E. Bachelet, R. Brunetaud, D. Coutsouradis, P. Esslinger, J. Ewald, I. Kvernes, Y. Lindblom, D.B. Meadowcroft, V. Regis (Eds.) High Temperature Materials for Power Engineering 1990, Pts 1 and 2, Kluwer Academic Publ, Dordrecht, 1990, pp. 1387-1396.

4. P. Caron, High Gamma' Solvus New Generation NickelBased Superalloys for Single Crystal Turbine Blade Applications, in: T.M. Pollock, R.D. Kissinger, R.R Bowman, K.A. Green, M. McLean, S.L. Olson, J.J. Schirra (Eds.) Superalloys 2000, Minerals, Metals \& Materials Soc, Warrendale, 2000, pp. 737-746.
5. H. Murakami, T. Yamagata, H. Harada, M. Yamazaki, The Influence of Co on Creep Deformation Anisotropy in Ni-Base Single Crystal Superalloys at Intermediate Temperatures, Materials Science and Engineering: A, 223 (1997) pp.54-58.

6. P. Caron, A. Escale, G. McColvin, M. Blackler, R. Wahi, L. Lelait, Development of New High Strength Corrosion Resistant Single Crystal Superalloys for Industrial Gas Turbine Applications, in: A. Strang (Ed.) Parsons2000 Advanced Mateirals for 21th Century Turbines and Power Plant, IOM Communications Ltd, Cambridge, U.K., 2000, pp. 847-864.

7. Patent US20050194068A1, Nickel-Based Superalloy Having Very High Registance to Hot-Corrosion for Monocrystalline Blades of Industrial Turbines

8. Patent WO2008046708A1, Nickel-Base Superalloys

9. A.W. Funkenbusch, J.G. Smeggil, N.S. Bornstein, Reactive Element - Sulfur Interaction and Oxide Scale Adherence, Metall. Trans. A, 16 (1985) pp.1164-1166.

10. J.L. Smialek, C.A. Barrett, J.C. Schaeffer, Design for Oxidation Resistance, in: ASM International, Materials Park (OH), 1997, pp. 598-602.

11. K. Harris, J.B. Wahl, Improved Single Crystal Superalloys, CMSX-4 La+Y and CMSX-486, in: K.A. Green, T.M. Pollock, H. Harada, T.E. Howson, R.C. Reed, J.J. Schirra, S. Walston (Eds.) Superalloys 2004, Minerals, Metals \& Materials Soc, Warrendale(PA), 2004, pp. 45-52.

12. A. Sato, J.J. Moverare, M. Hasselqvist, R.C. Reed, On the Mechanical Behaviour of a New Single Crystal Superalloy for Industrial Gas Turbine Applications Metallurgical and Materials Transactions A, doi: 10.1007/s11661-011-0995-2 (2012).

13. Thermotech Ni-Data Version 6, Thermotech Ltd./Sente Software, Surrey Technology Centre, 40 Occam Road, GU2 7YG, United Kingdom

14. J.J. Moverare, A. Sato, S. Johansson, M. Hasselqvist, R.C. Reed, J. Kanesund, K. Simonsson, On Localized Deformation and Recrystallization as a Damage Mechanisms During Thermomechanical Fatigue of Single Crystal Nickel-Based Superalloys., Adv. Mater. Res., 278 (2011) pp.357-362.

15. A. Sato, Y.L. Chiu, R.C. Reed, Oxidation of Nickel-Based Single-Crystal Superalloys for Industrial Gas Turbine Applications, Acta Mater., 59 (2011) pp.225-240.

16. R.T. Wu, R.C. Reed, On the Compatibility of Single Crystal Superalloys with a Thermal Barrier Coating System, Acta Mater., 56 (2008) pp.313-323.

17. K. Kawagishi, A. Sato, T. Kobayashi, H. Harada, Oxidation Properties for 2nd-5th Generation Ni-Base Single-Crystal Superalloys at 1023, 1173 and $1373 \mathrm{~K}$, J. Jpn. Inst. Met., 71 (2007) pp.313-319.

18. J.J. Moverare, S. Johansson, R.C. Reed, Deformation and Damage Mechanisms During Thermal-Mechanical Fatigue of a Single-Crystal Superalloy, Acta Mater., 57 (2009) pp. 2266-2276.

19. J.J. Moverare, M. Segersäll, A. Sato, S. Johansson, R.C. Reed, Thermomechanical Fatigue of Single-Crystal Superalloys - Influence of Composition and Microstructure, in: Superalloys2012, this volume. 